\title{
Community Health Advisor
}

National Cancer Institute

\section{Source}

National Cancer Institute. Community Health Advisor. NCI Thesaurus. Code C162160.

A healthcare worker in a local health, mental health, or social services department who formulates, organizes, directs, designs, or develops programs that generate improved community health outcomes. Work includes administrative direction and coordination of work with multiple community partners and non-profit agencies. 